
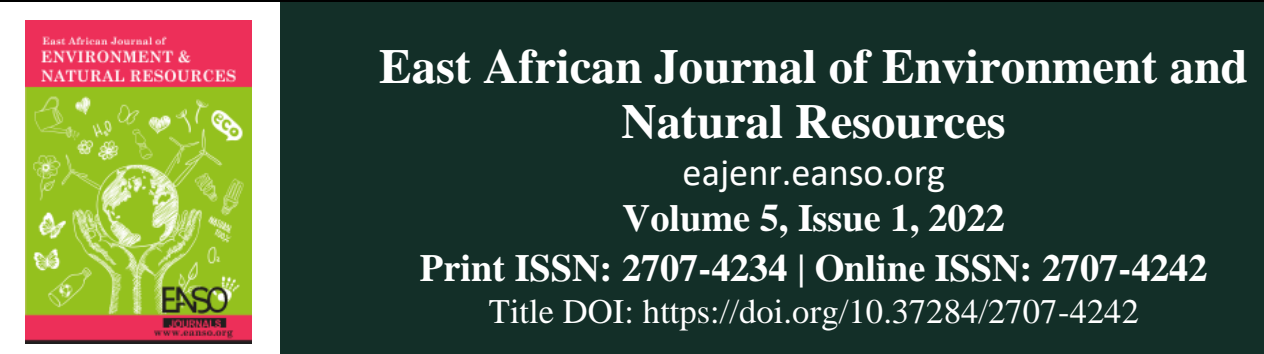

Original Article

\title{
Towards a Circular Economy: A Review on Asbestos Waste Management Regulations in Kenya.
}

\author{
Hope Nabango ${ }^{1} \&$ Dr. Christine Majale, $\mathrm{PhD}^{2 *}$ \\ ${ }^{1}$ Environmental Science, ISA Lille, 25-27 Rue de Fives, France. \\ ${ }^{2}$ Kenyatta University, P. O. Box 43844-00100, Nairobi, Kenya. \\ *Correspondence ORCID ID: https://orcid.org/0000-0002-0189-5606; email: hope.nabango@ student.junia.com.
}

Article DOI: https://doi.org/10.37284/eajenr.5.1.548

\section{Date Published: ABSTRACT}

14 February 2022 Kenya banned the use of asbestos in 2006, given its carcinogenic effects. Consequently, regulatory and institutional guidelines have been

Keywords: established to ensure the safe disposal of hazardous material. Yet, Kenya

Asbestos, infirmities. The goal of this article is to review the policy guidelines for

Circular Economy, disposal of asbestos and assess its robustness as a measure of socio-

Dissolution in Acids,

Hazardous Waste environmental risk reduction. The study utilises a systematic review of policy guidelines on asbestos, air, and water quality regulations against

Management,

Landfills, Policy, their implementation reviewed in Environmental Impact Assessment reports from 2013 to 2021. Studies assessing thermal and chemical treatment processes for asbestos are reviewed to assess the processes involved and acquire information based on efficiency in terms of cost, technological applicability, and minimal environmental effects. The

Thermal Conversion. review shows that more risks are inherent from landfilling, which is considered safe in the regulations. Examples include compromised standards of disposal and unforeseen risks arising from geologic activity that may create channels for leaching and other exposure pathways. This review proposes that the policy guidelines should 'rethink' and adopt conversion of the substance through processes such as dissolution in acids (and) or thermal conversion processes. The processes guarantee the elimination of the fibres and yield by-products that can be further processed, namely, glass and fertilisers. Additionally, they reduce waste and relieve landfills while optimising land use. Despite the high initial costs, the merits of the process offer significant trade-offs. There is a need for comprehensive data collection, especially on volume, detailed

34 | This work is licensed under a Creative Commons Attribution 4.0 International License. 
geophysical information, type of Asbestos Containing Material and coherence of policy guidelines. This sets precedence for the adoption of a circular economy which Kenya is determined to embrace. Also, it will present an opportunity for research and innovation that will contribute to a global knowledge base.

\section{APA CITATION}

Nabango, H. \& Majale, C. (2022). Towards a Circular Economy: A Review on Asbestos Waste Management Regulations in Kenya. East African Journal of Environment and Natural Resources, 5(1), 34-47. https://doi.org/10.37284/eajenr.5.1.548

\section{CHICAgO CITATION}

Nabango, Hope \& Christine Majale. 2022. "Towards a Circular Economy: A Review on Asbestos Waste Management Regulations in Kenya". East African Journal of Environment and Natural Resources 5 (1), 34-47. https://doi.org/10.37284/eajenr.5.1.548.

\section{HARVARD CITATION}

Nabango, H. Majale, C. (2022) "Towards a Circular Economy: A Review on Asbestos Waste Management Regulations in Kenya”, East African Journal of Environment and Natural Resources, 5(1), pp. 34-47. doi: 10.37284/eajenr.5.1.548.

\section{IEEE CITATION}

H. Nabango \& C. Majale, "Towards a Circular Economy: A Review on Asbestos Waste Management Regulations in Kenya”, EAJENR, vol.5, no. 1, pp. 34-47, Feb 2022.

\section{MLA CITATION}

Nabango, Hope \& Christine Majale. "Towards a Circular Economy: A Review on Asbestos Waste Management Regulations in Kenya". East African Journal of Environment and Natural Resources, Vol. 5, no. 1, Feb 2022, pp. 34-47, doi:10.37284/eajenr.5.1.548.

\section{INTRODUCTION}

The general term asbestos refers to typical fibrous minerals of two configurations: amphibole, a naturally occurring mineral with long thin fibres (actinolite, amosite, anthophyllite, crocidolite and tremolite) and chrysotile which is derived from serpentine minerals (Arce et al., 2017; Kim et al., 2015; Li et al., 2014; Shin et al., 2016; Zhang et al., 2016). The substance, which is known for its resilience to fire, degradation and heat was adopted in the 1960s and 1970s with extensive use as housing roofs, paints, and ceilings. Additionally, its non-flammability, thermal and electric insulation, stability under extreme circumstances, flexibility and robustness guaranteed its wide use in the automobile industry, where it was a standard component in clutch and brake linings (Gregson et al., 2010; Santee \& Lott, 2003).

Kenya, like most nations (Li et al., 2014; Spasiano \& Pirozzi, 2017), banned the use of asbestos in 2006 given its negative health implications (Abelmann et al. 2015; Kakooei and Normohammadi 2013; Perkins, Hargesheimer, and Fourie 2007; Stevulova et al. 2020). The Kenya national treasury reported that $10 \%$ (or $\$ 33$ million) of its national health budget is utilised to treat asbestos-related infirmities (Global Construction Review, 2016; Marete, 2020). Sadly, citizens are still exposed to this substance either occupationally or in their respective residences. The Kenya National Bureau of Statistics (2017) has mapped asbestos roofs in the country which is 197,217 sheets, with Nairobi having 15\% which is the highest nationally. This inventory is a good step towards addressing the risk and mainly the handling and disposal of these harmful products.

The ban on asbestos prompted the design for guidelines on the safe removal, handling and disposal of asbestos which should be done through a risk assessment and an Environmental Impact Assessment (EIA) from which a report should be provided to relevant authorities (Asbestos Guidelines, 2013). The regulations prohibit the reuse and recycling of the substance. Its primary objectives are to ensure the sound environmental disposal of asbestos through the removal, handling, and disposal and to encourage compliance with the overall environmental management code. It is commendable that the ban of asbestos is effected, there are guidelines to safely dispose of asbestos, 
and the Rotterdam Convention was ratified in 2005 (UNEP, 2017). However, the unprecedented effects of asbestos and ACM on health, the economy and the environment still loom, and these require sterner measures.

Hence, this review examines in detail the existing policies and their robustness in ensuring sustainable processing of ACM. Thereafter, it explores examples of feasible conversion processes of ACM that are widely applied and draws the strengths, weaknesses, and opportunities these techniques present in sustainably disposing of ACM. Consequently, EIA reports for proposed asbestos handling and disposal projects are reviewed to ascertain the strength of institutions and regulations in place. Lastly, recommendations are made regarding strengthening the guidelines and the impact on sustainable disposal of ACM to adopt a circular economy model.

\section{METHODOLOGY}

\section{The Policy Guidelines and Scientific Literature Examined in this Review}

The primary guideline examined is the National Guidelines on Safe Management and Disposal of Asbestos, 2013 version 1.0 available on the National Environment Management Authority database (https://www.nema.go.ke/images/Docs/G uidelines/Guidelines\%20asbestor.pdf). Also, the Environmental Management and Coordination (Water Quality) Regulations 2006, hereafter, Water Quality Regulations 2006, and the Environmental Management and Co-ordination (Air Quality) Regulations, 2013, hereafter, Air Quality Regulations, 2013, were also assessed to measure their strength and effectiveness in reducing risks associated with asbestos as shown in Figure 1. Both matrices (air and water) have been underscored by guidelines on asbestos to be potentially at risk of exposure to asbestos fibres hence their selection. Despite soil being highlighted, there are no guidelines stipulated to manage contaminants in soil (Koskei et al., 2017).

The review further sought to evaluate practical applications and methods of drastically minimising risks associated with the disposal of ACM. Thus, the authors searched for 'asbestos conversion processes' in peer-reviewed papers and patents. A general trend was observed; mechanical treatment, thermal conversion and chemical treatment are primarily applied in stabilising or inertization of asbestos fibres. However, thermal conversion and chemical treatment were selected for review, given more recent studies in this area. The goal was to assess the processes involved systematically and retrieve information based on efficiency in terms of cost, technological applicability, and minimal environmental effects in terms of resource input and by-product released. Literature on Life Cycle Analysis (LCA) was incorporated to assess the suitability of methods for conversion based on their impacts on costs, environmental, and socioeconomic impact. This factoring in the entire lifecycle of a project.

\section{Acquisition and Selection of Environmental Impact Assessment Reports}

An assessment of EIA statements was conducted to ascertain the robustness of the guidelines. All the reports are available in the public database under the EIA/SEA reports section in the given link (https://www.nema.go.ke/index.php?option=com_c ontent $\&$ view=article $\& i d=131 \&$ Itemid=290). The studies were selected from 2013 onwards after the guidelines on asbestos had been published. Only five reports are available; presumably, the database is not updated. Additional reports would have included EIA reports on rehabilitation of old houses constructed before 1999, but the three available (Mwenga \& Aronya, 2020; Wakoli et al., 2021; Bigogo et al., 2021) and on the website did not provide any information upon reading and searching keywords 'asbestos removal' even though the profile location for (Wakoli et al., 2021) clearly shows an asbestos house set for demolition. The authors did not eliminate the chances of a different study having been done for the asbestos removal, which has not been updated in the system. 
Figure 1: A schematic of the review process and publications applied to the study

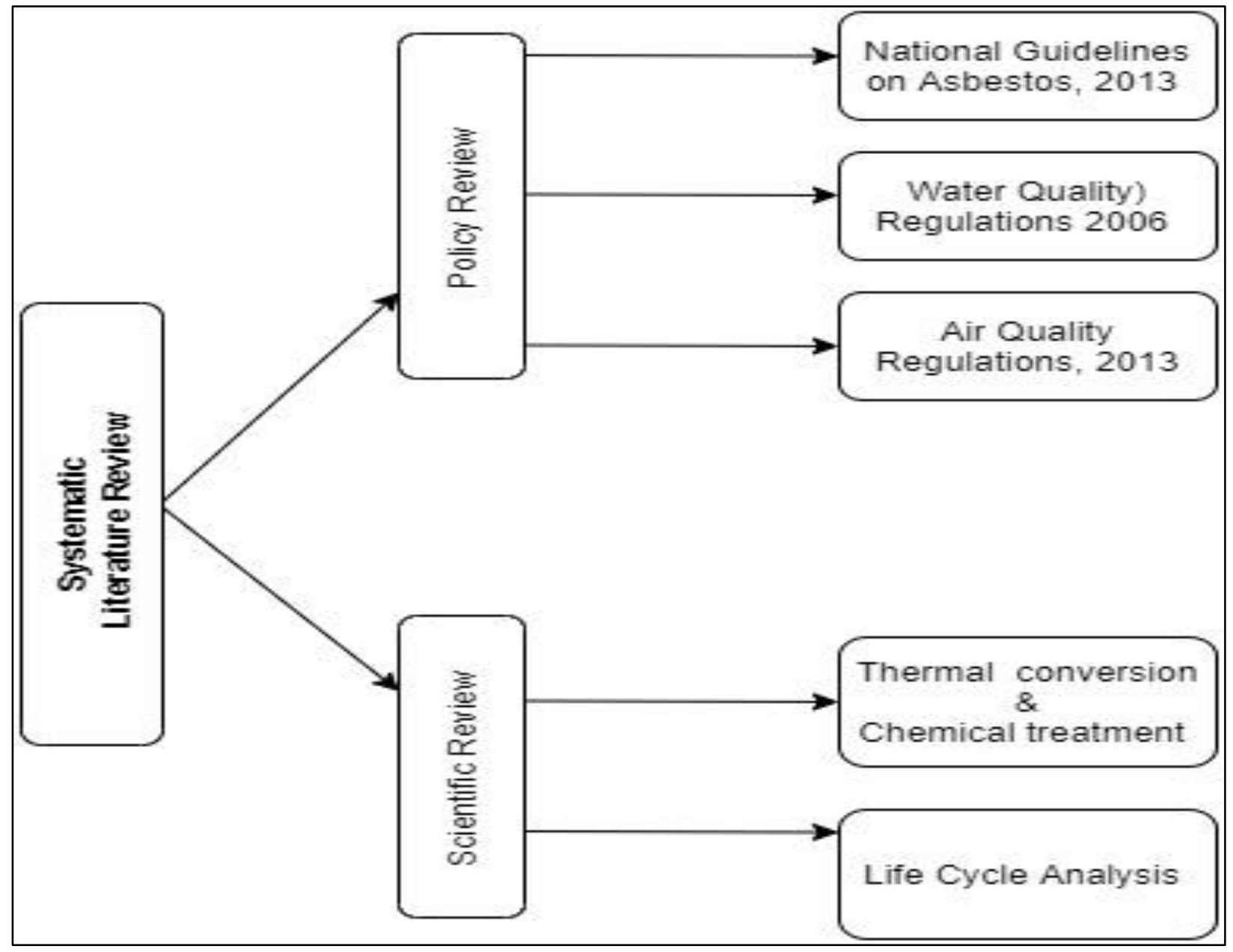

\section{RESULTS AND DISCUSSION}

\section{National Guidelines on Asbestos and its Limitations}

The regulations on asbestos describe the substance as hazardous. Generally, there are four prescribed methods for disposal of ACM in the respective regulations. These are embedded in the precautionary principle and are removal, handling, transportation and disposal and post-disposal, as summarised in Figure 2. Primarily, an inventory of ACM should be updated, and the National Environmental Management Authority (NEMA) should be informed through a duly filled form regarding a proposal to dispose of the ACM. Moreover, risk assessment ought to be conducted to ascertain the level of risk, protective equipment to be used, type of asbestos present including its composition, among other factors. No precise details are dispensed by the authority on the suitable equipment based on the risk attached. After removal, the substance is 'carefully wrapped' and transported to be buried in landfills by licensed asbestos handlers. Specifications on the sanitary landfill require licensing by the environmental authority, this is following meriting hydrogeophysical parameters. Whereas the guidelines provide a solution, it is temporary. There are unprecedented risks (Tomassetti et al. 2020) that could expose fibres of asbestos to the public. Additionally, leachate treating is not distinctively mentioned in the national guidelines but is presumed a norm since it is highlighted in the Waste Quality Regulations of 2006. Some environmental statements for proposed asbestos disposal have shown they seek to implement such after-care activities after highlighting potential infiltration fibres into adjacent waters, but acceptable and

37 | This work is licensed under a Creative Commons Attribution 4.0 International License. 
control limits for asbestos are not defined in the regulations. Moreover, these activities are likely to be costly.

The Water Quality Regulations of 2006 comprise a set of guidelines that apply to drinking water, water destined for use in industry, agriculture, recreation, wildlife and fisheries, effluent discharge, among other uses. Its goal is to prevent the pollution of water by prohibiting actions that directly or indirectly cause water pollution. The regulations subsequently provide eleven (11) schedules on quality standards and monitoring guidelines for various in relation to their uses. However, there is no indication for conducting fibre counts on asbestos even though its components such as cadmium, nickel, chromium etc., are indicated.
The Air Quality Regulations, 2013 is a set of guidelines geared towards prevention, control, and abatement of air pollution to ensure clean and healthy ambient air. The regulations define general prohibitions, permissible levels, controlled areas, stationary and mobile sources of air pollution as well as occupational health limits. Additional information on methods of measurement, analysis and laboratory are provided in the $11^{\text {th }}$ schedule of the guidelines. For provisions on managing ACM, the guidelines provide international standards for stationary source emissions-fibre count method (KS ISO 10397), KS ISO 10312 and KS ISO 13794 and for ambient air through Direct and Indirect Transfer Transmission Electron Microscopy, respectively

Figure 2: A schematic showing the procedure for handling and disposing of ACM in Kenya

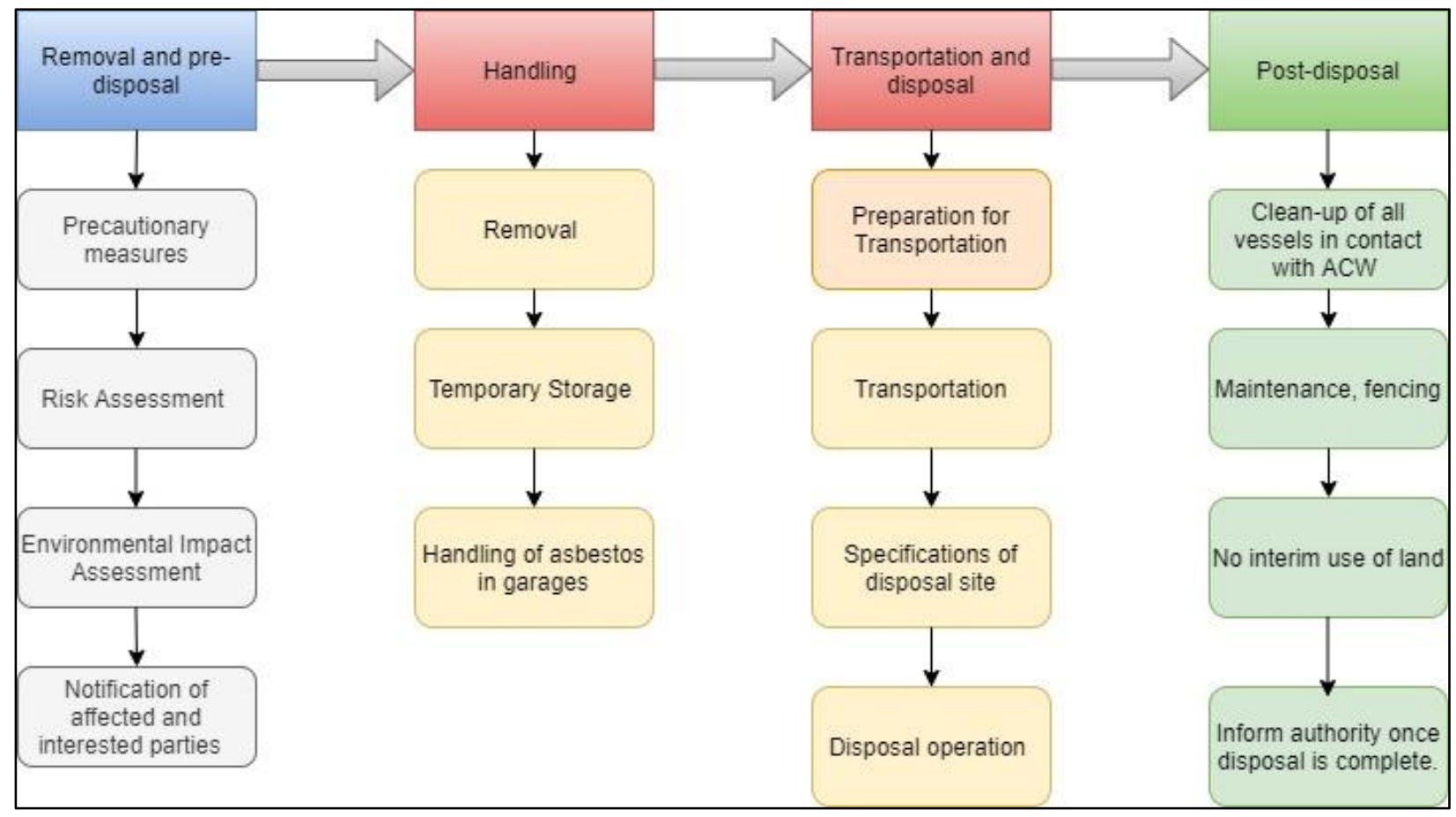

The existing methods for managing asbestos are rightly geared towards safety and environmental protection. However, landfilling of asbestos is not good enough a solution; in fact, it only extends current socio-environmental risks to future generations (Kusiorowski et al. 2013). Hence, the following scientific literature review examines treatment methods for asbestos. These are dissolution in acids and thermal conversion processes, which both eliminate the harmful fibres while forming new substances that can be utilised in other industries.

Innumerable studies have been conducted to elucidate the safe ways of disposing of asbestos (Kusiorowski et al., 2012; Paolini et al., 2019; Pawełczyk et al., 2017). Thermal conversion has been widely assessed as a suitable solution for ACM. The process involves the conversion of waste 
through a high thermal medium of $400{ }^{\circ} \mathrm{C}-1200{ }^{\circ} \mathrm{C}$ depending on the asbestos content in the sample (Kusiorowski et al. 2015). Table 1 shows the merits and challenges of conversion processes for ACM. The high temperatures which is a primary limitation of the process, completely destroy the asbestos fibres producing an inert homogenous and stable substance also known as silicate glass( $\mathrm{Li}$ et al., 2014; Spasiano \& Pirozzi, 2017). Similarly, Gualtieri et al. (2008) experimentally examined the direct temperature-induced transformation of cement asbestos. After subjecting the sample to $1200{ }^{\circ} \mathrm{C}$, they established the production of inert substances with no fibrous asbestos as seen under optical and electron microscopy. Rather, the product obtained had larger content of aluminium, iron, and magnesium and was safe for recycling in the production of stoneware tile mixtures. The study echoes that despite high energy costs, other options such as milling of the substance to increase reactivity in chemical processes is a high-risk activity; hence thermal conversions are much safer.

Iwaszko et al. (2021) performed vitrification of ACM using a waste glass with a composition ratio of 50:50 of the mass of ACM waste to the mass cullet. After subjecting the sample to $1400{ }^{\circ} \mathrm{C}$ for 90 minutes, they established that an amorphous material was produced with a hardness of $79 \%$ more than the glass and it had a low leachability. Moreover, the results showed that chrysolite was not present when observed under the spectroscopic $\mathrm{X}$-ray, affirming that the fibres had been destroyed. Marian et al. (2021) investigated thermal efficacy inertization through x-ray diffraction, scanning and transmission electron microscopy for chrysolite and crocidolite fibres. They report for the first time a 15minute inertization, which means lower energy consumption for the process and echo that with additional investigations and factoring Life Cycle Analysis (LCA), it is possible to break even. They report on another patented study ( Lucchese 2014.)which shows that $0.25 \mathrm{kWh}$ of energy is consumed per $\mathrm{kg}$ of ACM. This is suitable for and highly feasible even compared to the most functional system in the European Union located in France, INERTAM Moncenx, whose operational costs are at $€ 1000-2500$ depending on the water content. Similar studies (Bonizzoni and Vassallo 2002; Colombo et al. 2003; Haugsten and Gustavson 2000; R.a et al. 2019) have shown that the process, while being efficient in destroying the harmful substance and availing the inert materials for utilisation, in other industries, significantly reduced volume of waste into landfills while stirring a circular-economy (Zoraja et al. 2021) as shown in Table 1.

Applications of LCA have been explored recently in various treatments of ACM (Mercante et al., 2021; Young-Corbett, 2012). A comparative LCA by Lachat et al. (2021) of two houses staged for demolition showed that the most impactful aspect is the asbestos removal, transport and treatment that accounted for $35 \%$ of total global warming. The study shows $255 \mathrm{~km}$ is covered by the trailer to transport the material to a landfill and additional emissions arise from staff transportation, energy from equipment and other associated services. This study not only spotlights the need to hasten transition into biofuel but also highlights the profound need to perform life cycle inventory. In fact, such factual figures should be pre-requisites for such projects as opposed to descriptive EIA reports. Similarly, Pini et al. (2021) compare the conventional landfill process of asbestos to the thermal inertization process in Italy. The life cycle inventory shows that inertization is a preferred solution because it yields secondary materials for other industries. It is coupled with environmental impacts such as freshwater toxicity from the electrolysis process. However, this is a consequence of the background model for the ecoinvent process. Overall, the study ascertained that human health impacts were reduced by $42.48 \%$, mainly attributed to the secondary inert material production and, they established break-even in the impacts of the thermal inertization function system and the co-product which is vital for the recycling process and notably for a circular economy. 
Table 1: Merits and Demerits of adopting conversion processes for asbestos and ACM

\begin{tabular}{|c|c|}
\hline $\begin{array}{l}\text { Merits of adopting conversion processes for } \\
\text { asbestos and ACM }\end{array}$ & $\begin{array}{l}\text { Challenges associated with conversion processes } \\
\text { for asbestos and ACM }\end{array}$ \\
\hline $\begin{array}{l}\text { - An inert product is produced with no impacts to } \\
\text { the environment- water, soil, air, and human } \\
\text { beings }\end{array}$ & $\begin{array}{l}\text { - Cost of installation and operation } \\
\text { - High thermal environment for vitrification can be } \\
\text { difficult to achieve or too costly. } \\
\text { - High volume of regents }\end{array}$ \\
\hline - Landfill tax avoidance. & - Both require adequate skills to implement \\
\hline $\begin{array}{l}\text { - Reduced volume of waste that would quickly fill } \\
\text { up landfills }\end{array}$ & - Occupational risks \\
\hline $\begin{array}{l}\text { - Takes care of long-term threat and risk of } \\
\text { exposure to asbestos and its associated } \\
\text { infirmities. }\end{array}$ & $\begin{array}{l}\text { - Finding a geographic location that can be } \\
\text { equidistant for national processing otherwise } \\
\text { possible exposure of fibres through long- } \\
\text { distance exposure. }\end{array}$ \\
\hline
\end{tabular}

- Reduced budgetary allocations for treating asbestos-related diseases

- Development of a new substance to be utilised in other industrial activities/processes

- Destruction of other wastes containing asbestos

- Presents novel ideas and technology to sustainably manage ACM and other hazardous wastes

- Vitrification does not require further purification

- Presents an opportunity for further Risk assessment and monitoring procedures in the country to reduce risks

- Increased wealth of knowledge in managing hazardous substances

- Job creation

\section{Dissolution in Acids}

Tan et al. (2021) transformed chrysotile asbestos tailings to struvite and silicate salts using phosphates of ammonia, potassium, and calcium with the goal of utilising them in citric acid-soluble fertiliser. Their results showed that it is effective to mill chrysolite with phosphates of magnesium and calcium since they produced high nutrient releases in citric acid (that is, $94.54 \% \mathrm{Mg}, 96.79 \% \mathrm{~N}$, $96.97 \% \mathrm{P}$, and $14.02 \% \mathrm{Si}$ in $2 \%$ citric acid) than in water $(0 \% \mathrm{Mg}, 9.37 \% \mathrm{~N}, 2.02 \% \mathrm{P}$, and $9.86 \% \mathrm{Si})$. It was evident that this method is highly environmentally friendly with far-reaching effects on agricultural production as nutrients do not dissolve in water. In a similar study (Borges and Wypych 2019), chrysotile asbestos was milled with potassium phosphates producing impressive results.
They milled two sets of chrysotile asbestos cement, one without the potassium phosphate and the other set with a mixture for periods ranging between 1 and 16 minutes. They confirmed quartz and calcite were predominant and resistant to milling where phosphates were not used, whereas in the mixture with phosphates, only low-intensity peaks were observed ascertaining the positive effect of potassium phosphate in amorphisation. Upon evaluating the performance of the samples on aqueous acetic and deionised water solutions, they similarly observed high nutrient releases of calcium and magnesium hence confirming the essential use of amorphised asbestos in acid soil conditioning and its minimal impact on aquatic environments.

Baigenzhenov et al. (2015) explored another valueadded technology of recycling waste generated from chrysotile to produce magnesium chloride. They 
conclude that it is a preferred technology due to a high amount of magnesium content acquired (20$25 \%$ ), an inexhaustible and ample supply of serpentine for processing and the cost of raw material is low. Through a dyad process of leaching magnesium from serpentine and silicon, thereby reducing fibres of asbestos, the tailings are subjected to hydrochloric acid. Their results showed 99\% purity of the silicate and consistency in the quality. The process requires adequate skill and techno-how and may initially be a challenge to adopt due to requiring high volumes of reagents as highlighted in Table 1. While ascertaining this, (R.a et al. 2019) show that the resultant products and its quality that can stir an economy far outweigh the challenges.

\section{Review of Environmental Impact Assessment reports}

The results of the reports are summarised in Figure 3. Volume was a parameter sought after to determine the extent of data collection that would feed the remainder stages/activities of the lifecycle. It was evident that only one study (Taure, 2018) provided complete data defining landfill volume and approximate ACM that were destined to the landfill. Coupled with (Kituta \& Nderitu, 2020) which only provided data on landfill volume, both mentioned that the sites are meant to be utilised continuously and not 'one-off deposition.' It is echoed that comprehending the quantity that goes into the landfill is essential in valuing the landfill for future use of the resource(decommissioning). In all the reports, none shows the type of asbestos, but a generalised description sums up the product as the roofing sheet. It's worth noting that the serpentine or fibrous is considered injurious to cells since it causes proliferation, oxidant release, and inflammation, whereas the fibrous dust 'amphibole' is known for its biopersistence and the potential to induce malignant disease following deposition of fibres in the peripheral airways and migration of fibres to the serosal membrane (Militello, Gaggero, and La Maestra 2021; Sporn 2014). In the event that landfill mining is taken up, with the valuation of products having been fully understood in the near future, this procedure will warrant assessments and measurements to valorise the product, a process that is being popularised in the European Union known as RAWFILL (Neculau et al., 2019a; Nuculau, 2019b). This study shows that with finer details being assembled in an inventory database, it will be efficient to valorise the waste in future through the methods herein discussed or otherwise.

Figure 3: A chart showing number of reports capturing parameters associated with sustainable disposal of ACM

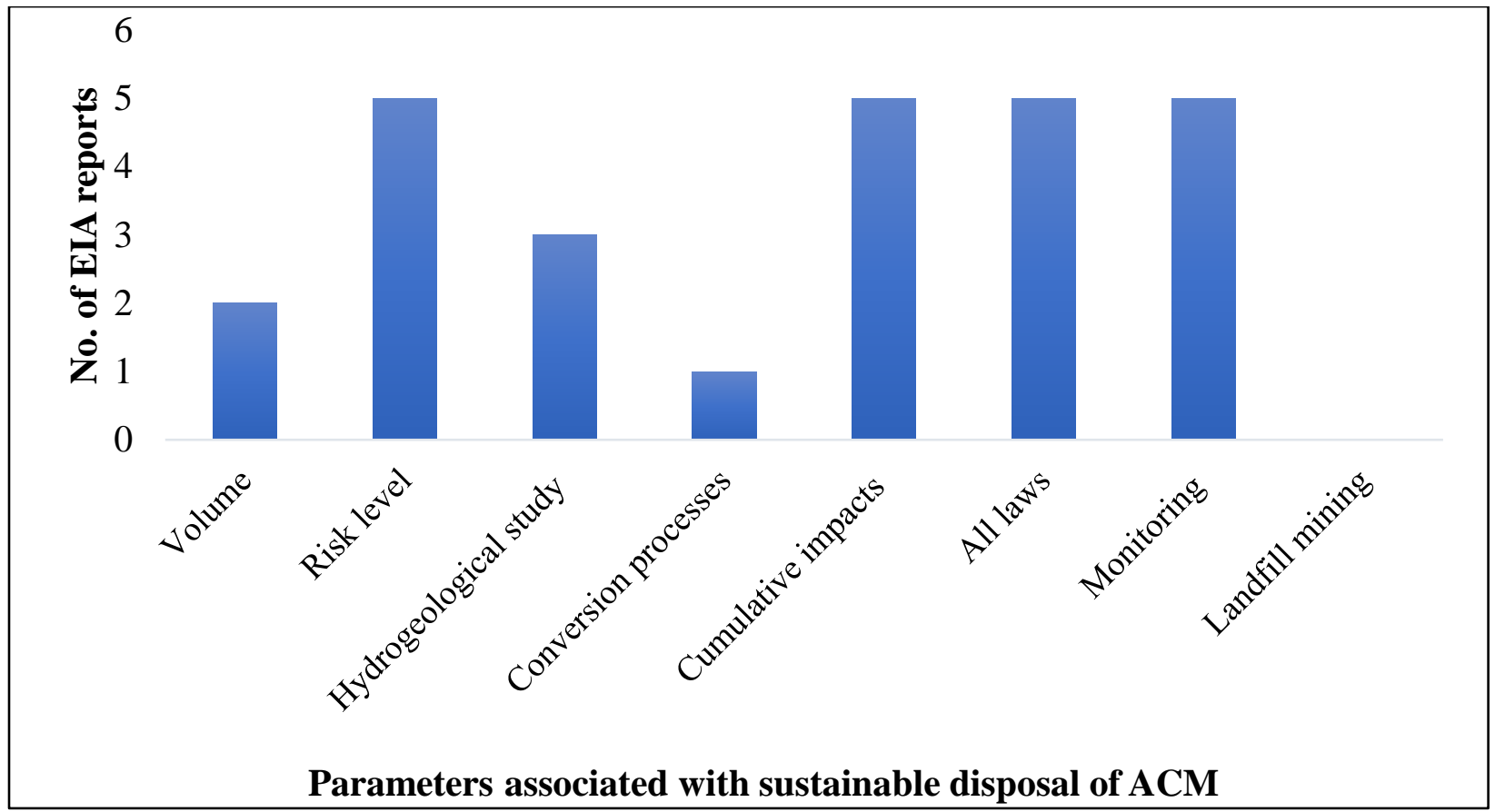

41 This work is licensed under a Creative Commons Attribution 4.0 International License. 
A coherent attribute of these reports is that sanitary landfilling of ACM is high risk and warrants due diligence in handling to disposal. Such include the EIA report, a risk assessment report and hydrogeological assessment that confirms risks posed to water bodies are minimal. Two studies did not provide details on the hydrogeological study although it is possible these were submitted in hardcopy. Mwenga et al. (2021) showed no aquifer was present and consequently did not proceed to define after-care guidelines, especially leachate treating. Kimutai et al. (2020) showed the risk of waterlogging is high which means it's likely to undergo degradation as a natural asbestos ore showed in a recent study (Avataneo et al. 2021) if other parameters are not bolstered. Whereas it is important that detailed lateral and vertical flows of water are defined, additional measures such as channelling of surface water flow and leachate treatment, as defined by law, should be emphasised to minimise risks of pollution. On the other hand, it is these costs that make landfilling of ACM unattractive because costs of monitoring are high, as shown by the reports, the cost ranges from $\$ 400$ per month for both air and water monitoring up to $\$ 5000$ (presumably annually), notwithstanding other costs inclusive of land rates, insurance etc. These high costs of maintenance, in fact, are echoed by the reports as a possible cause for compromised standards which could be detrimental to environmental quality (Makota \& Mwaniki, 2021; Kimutai et., al 2020).

The study measured the knowledge of experts on alternatives to landfilling through assessing the chapter on 'Alternatives.' Makota and Mwaniki (2021) agree that feasible baseline changes could occur hence compromising environmental quality and safety, whereas Kituta \& Nderitu (2020) consider simple and economical technology which is the landfill as the best solution on long-term. The other studies prioritise the landfilling or 'project option' arguing that it 'reduces/eliminates risks of the fibres exposures to the populace.' Kimutai et al. (2020) showed alternative methods of disposal could be explored but argued that fibres are immobile in soil which has recently been disapproved (Mohanty, Salamatipour, and Willenbring 2021). On the other hand, no report has explored in literature alternative processes as herein discussed 'thermal conversion and acidification'. It is vital that designers and sustainability planners explore such solutions and recommend their findings to respective clientele while informing the regulatory authority. This will stir a paradigm shift towards embracing and actively seeking sustainable solutions herein, a circular economic model.

Cumulative impacts of landfilling are unanimously agreed ranging from greenhouse gas emissions in transportation, particulate matter escaping from the landfills and during removal, risk of the poor lining of landfills, unregulated wasted being dumped onsite, other wastes which include anything that encounters the ACM, occupational risks of workers and clean-up activities. Similar conclusions have been discussed by LCA studies herein (Lachat et al. 2021). All reports have identified the monitoring measures for various matrices with Air Regulations of 2013 taking precedence in air monitoring. Despite having defined measures required for stationery and ambient air monitoring, the reports do not show characterisation of the fibres as would be if the respective tests (KS ISO 10312 and KS ISO 13794) were undertaken. On the other hand, if the results are indicated in the Risk Assessment report, coherence should be imminent and such information provided in the overall EIA report.

Water monitoring is also underscored by the reports on 'monitoring activities which will follow the guided values provided in the asbestos guidelines' under the Water Regulations, 2006. However, the guidelines show that asbestos manufacturing industries should conduct bio-physicochemical analysis and no count of asbestos in water through Scanning and Transmission Electron Microscopy SEM/TEM analysis is mentioned, contrary to the Air Quality Regulations, 2013. This limits the functionality of this law and undermines the relevant application. EIA, Kituta \& Nderitu (2020), however, highlight an effective toxicity analysis Bioassay test for $90 \%$ survival of fish. The limiting factor is that its acute toxicity test at 96 hours, whereas the effects of asbestos are long-term. Soil monitoring techniques follow similar applications; hence the monitoring provided by the guideline is not sufficient. In general, it is observed that there is no coherence in the guidelines such as the disposal guidelines and Water Quality Regulations, 2006 failing to warrant asbestos counts, whereas the Air Quality Regulations provide guidance on such. 
Despite making provisions for hydrogeological surveys and other physical barriers against water contamination, the inherent risk of leachate exposures cannot be shoved off. A comprehensive assessment of risks needs to be factored in and these should be aided by a life cycle analysis approach.

Consequently, a revision of terms to require this analysis only increases costs to the proponent. Moreover, chances are only a handful of laboratories offer these services. Whereas thermal conversion processes will also require microscopy (Bonizzoni and Vassallo 2002; Borges and Wypych 2019; Iwaszko et al. 2021; Kusiorowski et al. 2015; R.a et al. 2019; Tan et al. 2021), it would be a procedural aspect to ascertain that fibres are denatured and ready for utilisation in other fields and not a continuous(annual) procedure. In fact, the risk will have been transferred to the conversion facility. Thermal conversion is heavily debatable as an option for the circular economy because it eliminates nutrients or raw materials from the loop; however, this study argues that the risks linked with handling ACM are far too high to be transferred through generations hence, producing useful alternative by-products such as glass, fertilisers, fillers for other industries, should be a significant factor. Additionally, it presents opportunities for innovation and creativity that should indeed stir the pursuit of sustainable solutions. This will also impact other hazardous substances.

\section{CONCLUSION}

This study has reviewed and explored two common practices of managing asbestos waste; vitrification and dissolution in acids, especially with an emphasis on reuse and recycle processes. Consequently, the review has explored the strength of existing institutions and policy guidelines on the management of ACM in waste in Kenya. Whereas it is worth acknowledging that the policy seeks to offer sustainable management and risk reduction of handling and disposing of the substance, it is evident that the methods discussed herein are superior. Firstly, conversion of asbestos wastes will ensure complete destruction of fibres providing an inert material that can also be utilised in other industries. Since Kenya is geared towards adopting the circular economy, revising the existing policy will provide an opportunity to adopt the framework.
Additionally, the process eliminates not only asbestos but other substances such as polychlorobiphenyls, among other harmful substances. Therefore, this will present an opportunity for comprehensive mapping of asbestos and ACM with the aim of reducing risk to Kenya's populace. Secondly, the benefits associated with a clean environment, reduced burden on the economy from spending on treatment of asbestos-related diseases will contribute to a sustainable society.

The review of EIA reports shows considerable effort indeed is put to reduce impacts of ACM through sustainable solutions, but risks are even more inherent. Compromised standards arising vis a vis high costs of maintenance will sabotage the quality and safety of the environment. Monitoring measures for soil and water do not address the risk of asbestos fibres and hence they limit attaining the goal of sustainable disposal. Emphasis should be created on data collection, especially the volume of ACM and type of material. Geophysical information can also be improved with time. It is evident that most practitioners have not embraced greener solutions for asbestos handling in Kenya, and hence it is a call to environmental experts and sustainability practitioners to investigate these solutions, recommend them to clients and the relevant authorities to stir the exodus towards a circular economy.

It is vital to highlight that the technologies herein discussed, thermal conversion and dissolution in acids are not entirely novel ideas that are farfetched; hence, through careful assessments and evaluation, they can be adopted. The life cycle analysis of individual conversion processes should be conducted with all variables modelled clearly understood to ascertain cut-offs and trade-offs that can be gained. This will present an opportunity for research, creativity and innovation that will contribute to a global knowledge base.

\section{REFERENCES}

Abelmann, A., Glynn, M. E., Pierce, J. S., Scott, P. K., Serrano, S., \& Paustenbach, D. J. (2015). Historical ambient airborne asbestos concentrations in the United States-an analysis of published and unpublished literature (1960s2000s). Inhalation Toxicology, 27(14), 754-766. 
Arce, G. L., Neto, T. G. S., Ávila, I., Luna, C. M., \& Carvalho Jr, J. A. (2017). Leaching optimisation of mining wastes with lizardite and brucite contents for use in indirect mineral carbonation through the $\mathrm{pH}$ swing method. Journal of Cleaner Production, 141, 1324-1336.

Avataneo, C., Belluso, E., Capella, S., Cocca, D., Lasagna, M., Giovanni, P., \& De Luca, D. (2021). Groundwater Asbestos Pollution From Naturally Occurring Asbestos (Noa): a Preliminary Study on the Lanzo Valleys And Balangero Plain Area, Nw Italy. Italian Journal of Engineering Geology and Environment, 1 (2021), 5-19.

Baigenzhenov, O. S., Kozlov, V. A., Luganov, V. A., Mishra, B., Shayahmetova, R. A., \& Aimbetova, I. O. (2015). Complex processing of wastes generated in chrysotile asbestos production. Mineral Processing and Extractive Metallurgy Review, 36(4), 242-248.

Bigogo, C., Langat, W., Nyayieka, B., Wakaimba, J., Okong'o, V., \& Kinaro, E. (2021). Environmental and Social Impacts Assessment Study Report for the Proposed Kakamega Staff Housing Project at Mudiri Estate, in Kakamega Town. NEMA. https://www.nema.go.ke/images /Docs/EIA_1890-1899/EIA_1897\%20KAKA MEGA\%20HOUSING\%20PROJECT_2340min.pdf

Bonizzoni, G., \& Vassallo, E. (2002). Plasma physics and technology; industrial applications. Vacuum, 64(3-4), 327-336.

Borges, R., \& Wypych, F. (2019). Potential slowrelease fertilisers and acid soil conditioners obtained by one-pot mechanochemical activation of chrysotile: cement roofing sheets with K 2 HPO 4. Journal of the Brazilian Chemical Society, 30, 326-332.

Colombo, P., Brusatin, G., Bernardo, E., \& Scarinci, G. (2003). Inertization and reuse of waste materials by vitrification and fabrication of glass-based products. Current Opinion in Solid State and Materials Science, 7(3), 225-239.
Global Construction Review (2016). Kenya faces cancer epidemic caused by asbestos roofs. https://www.globalconstructionreview.com/keny a-faces-cancer-epid7emic-caus7ed-asbe7stos/

Gualtieri, A. F., Cavenati, C., Zanatto, I., Meloni, M., Elmi, G., \& Gualtieri, M. L. (2008). The transformation sequence of cement-asbestos slates up to $1200 \mathrm{C}$ and safe recycling of the reaction product in stoneware tile mixtures. Journal of hazardous materials, 152(2), 563-570.Haugsten, K. E., \& Gustavson, B. (2000). Environmental properties of vitrified fly ash from hazardous and municipal waste incineration. Waste Management, 20(23), 167-176.

Kenya National Bureau of Statistics (KNBS). (2017). Housing Roof Material by County and District. https://www.knbs.or.ke/?wpdmpro=ho using-roof-material-by-county-and-district

ISO, I. (1999). 13794: Ambient air--Determination of asbestos fibres--Indirect-transfer transmission electron microscopy method. British standards institution.

ISO 10397:1993(EN), Stationary source emissions-Determination of asbestos plant emissions-Method by fibre count measurement. Retrieved 10 January 2022, from https://www.iso.org/obp/ui/\#iso:std:iso:10397:e d-1:v1:en

Iwaszko, J., Lubas, M., Sitarz, M., Zajemska, M., \& Nowak, A. (2021). Production of vitrified material from hazardous asbestos-cement waste and CRT glass cullet. Journal of Cleaner Production, 317, 128345.

Kakooei, H., \& Normohammadi, M. (2013). Asbestos exposure among construction workers during demolition of old houses in Tehran, Iran. Industrial health, 2012-0118.

Kenya Gazette. Environmental Management and Co-ordination (Air Quality) Regulations, 2013

Kenya Gazette. Environmental Management and Co-ordination (Water Quality) Regulations, 2006. 
Kim, Y. C., Hong, W. H., \& Zhang, Y. L. (2015). Development of a model to calculate asbestos fiber from damaged asbestos slates depending on the degree of damage. Journal of Cleaner Production, 86, 88-97.

Kimutai, M., Onana, P., Kaguru, O., \& Amoth L. (2020). Environmental and Social Impact Assessment (EIA) Study Report for the Proposed Asbestos Disposal Site (Land Fill) on LR No. 1885, Suna West/Wasimbete/Buhembu in Migori County. NEMA. https://www.nema.go.ke/image s/Docs/EIA_1800-1809/EIA_1783\%20STUD Y\%20FOR\%20THE\%20PROPOSED\%20ASB ESTOS\%20DISPOSAL\%20SITE-min.pdf

Kituta, I. P., \& Nderitu, W. (2020). Environmental and Social Impacts Assessment Study Report for The Proposed Study.

Koskei, S., Cheng, Y., \& Shi, W. L. (2017). Critical review of the current status of soil contamination in Kenya. International Journal of Environmental Monitoring and Analysis, 5(2), 14-24.

Kusiorowski, R., Zaremba, T., Gerle, A., Piotrowski, J., Simka, W., \& Adamek, J. (2015). Study on the thermal decomposition of crocidolite asbestos. Journal of thermal analysis and calorimetry, 120(3), 1585-1595.

Kusiorowski, R., Zaremba, T., Piotrowski, J., \& Adamek, J. (2012). Thermal decomposition of different types of asbestos. Journal of thermal analysis and calorimetry, 109(2), 693-704.

Kusiorowski, R., Zaremba, T., Piotrowski, J., \& Gerle, A. (2013). Thermal decomposition of asbestos-containing materials. Journal of thermal analysis and calorimetry, 113(1), 179188.

Lachat, A., Mantalovas, K., Desbois, T., YazoghliMarzouk, O., Colas, A. S., Di Mino, G., \& Feraille, A. (2021). From Buildings' End of Life to Aggregate Recycling under a Circular Economic Perspective: A Comparative Life Cycle Assessment Case Study. Sustainability, 1 3(17), 9625.
Li, J., Dong, Q., Yu, K., \& Liu, L. (2014). Asbestos and asbestos waste management in the AsianPacific region: trends, challenges, and solutions. Journal of cleaner production, 81, 218-226.

Lucchese, N. (2014). Il rischio amianto oggi: stato dell'arte e prospettive future.

Makota, A., \& Mwaniki, A. (2021). Environmental and Social Impacts Assessment Study Report for The Proposed Tai Lifestyle - Voi- Asbestos Handling combined. NEMA. https://www.nema .go.ke/images/Docs/EIA_1830- 1839/EIA\%201 831\%20TAI\%20LIFESTYLE\%20- \%20VOI$\%$ 20ASBESTOS $\% 20$ HANDLING\%20\%20\%2 0combined.pdf

Marete, G. (2020). Kenya: Concerns Raised Over Buildings with Asbestos Roofing in Meru. AllAfrica. https://allafrica.com/stories/2020013 00690.html

Marian, N. M., Giorgetti, G., Magrini, C., Capitani, G. C., Galimberti, L., Cavallo, A., ... \& Viti, C. (2021). From hazardous asbestos containing wastes $(\mathrm{ACW})$ to new secondary raw material through a new sustainable inertization process: A multimethodological mineralogical study. Journal of Hazardous Materials, 413, 125419.

Mercante, I., Ojeda, J. P., \& Alejandrino, C. (2021). Life Cycle Assessment of Asbestos Waste Management Scenarios: Case Study in Argentina. Journal of Hazardous, Toxic, and Radioactive Waste, 25(4), 05021007.

Militello, G. M., Gaggero, L., \& La Maestra, S. (2021). Asbestiform amphiboles and cleavage fragments analogues: overview of critical dimensions, aspect ratios, exposure and health effects. Minerals, 11(5), 525.

Mohanty, S. K., Salamatipour, A., \& Willenbring, J. K. (2021). Mobility of asbestos fibers below ground is enhanced by dissolved organic matter from soil amendments. Journal of Hazardous Materials Letters, 2, 100015.

Mwenga, M. A., \& Aronya, F. (2020). Environment \& Social Impact Assessment Study Report for 
Proposed Buxton Affordable Housing Units on L.r No. Mombasa/xvii/625 \& 985 Situated at Buxton, Mombasa (Volume 1). NEMA. https://www.nema.go.ke/images/Docs/EIA_180 0-1809/ESIA_1804\%20Buxton\%20Housing\% 20Project_SR\%201951-min.pdf

National Guidelines on Safe Management and Disposal of Asbestos (2013). https://www.nema.go.ke/images/Docs/Guidelin es/Guidelines\%20asbestor.pdf

Neculau, C., Nguyen, F., Caterina, D., \& Manrique, I. I. (2019a). Innovative Landfill Characterisation: The Case Study of Onoz Landfill (Wallonia, Belgium). In Proceedings of the $17^{\text {th }}$ International Waste Management and Landfill Symposium. CISA Publisher.

Nuculau, C., De Rijft, R., Wille, E. \& RAWFILL Team. (2019b). Rawfill Project: Innovative Characterisation of Landfills and Smart Decision-making as Part of the Circular Economy, Through Landfill Mining Operations. In Proceedings of the $17^{\text {th }}$ International Waste Management and Landfill Symposium. CISA Publisher.

Taure, K. (2018). Environmental Impact Assessment Study Report for Proposed Asbestos Disposal Site (Land Fill) on Unregistered Parcel of Land,in Kibaoni Village, Ndugumnane Sub Location, Ganze, Kilifi County. NEMA. https://www.nema.go.ke/images/Docs/EIA_153 0 -

1539/NEMA_1539\%20Asbestos\%20Disposal\% 20Site\%20Kilifi\%20County\%20Report.pdf

Paolini, V., Tomassetti, L., Segreto, M., Borin, D., Liotta, F., Torre, M., \& Petracchini, F. (2019). Asbestos treatment technologies. Journal of Material Cycles and Waste Management, 21(2), 205-226.

Pawełczyk, A., Božek, F., Grabas, K., \& Chęcmanowski, J. (2017). Chemical elimination of the harmful properties of asbestos from military facilities. Waste Management, 61, 377385 .

Perkins, R. A., Hargesheimer, J., \& Fourie, W. (2007). Asbestos release from whole-building demolition of buildings with asbestos-containing material. Journal of occupational and environmental hygiene, 4(12), 889-894.

Pini, M., Scarpellini, S., Rosa, R., Neri, P., Gualtieri, A. F., \& Ferrari, A. M. (2021). Management of Asbestos Containing Materials: A Detailed LCA Comparison of Different Scenarios Comprising First Time Asbestos Characterization Factor Proposal. Environmenta l science \& technology, 55(18), 12672-12682.

Santee, K., \& Lott, P. F. (2003). Asbestos analysis: a review. Applied Spectroscopy Reviews, 38(3), 355-394.

Shayakhmetova, R. A., Mukhametzhanova, A. A., Samatov, I. B., \& Akbayeva, D. N. (2019). Technogenic raw materials for the production of magnesium and silicon- containing compounds. Machines. Technologies. Materials., 13(2), 9092.

Shin, H., Choi, Y., Jeon, B., Ha, J., Sun, Y., \& Park, W. (2016). A study of asbestos stabiliser treatment considering the actual environment of ceiling materials. Journal of Korean Society of Occupational and Environmental Hygiene, 26(2), 139-146.

Spasiano, D., \& Pirozzi, F. J. J. O. E. M. (2017). Treatments of asbestos containing wastes. Journal of environmental management, 204, 82-91.

Sporn, T. A. (2014). The mineralogy of asbestos. Pathology of asbestos-associated diseases, 1-10.

Stevulova, N., Estokova, A., Holub, M., Singovszka, E., \& Csach, K. (2020). Characterisation of demolition construction waste containing asbestos, and the release of fibrous dust particles. Applied Sciences, 10(11), 4048 .

Tan, Y., Zou, Z., Qu, J., Ren, J., Wu, C., \& Xu, Z. (2021). Mechanochemical conversion of chrysotile asbestos tailing into struvite for full elements utilisation as citric-acid soluble fertiliser. Journal of Cleaner Production, 283, 124637.

46 This work is licensed under a Creative Commons Attribution 4.0 International License. 
United Nations Environment Programme (2017): Status of Ratifications. http://www.pic.int/?tabi $\mathrm{d}=1072$ accessed on 2021-09-24.

Wakoli, E. Waweru, J., \& Ayeket, I. (2021). Environmental and Social Impacts Assessment Study Report for the Proposed Construction of Residential Apartments (Bondeni Affordable Housing Estate) On Nakuru County Government Housing Estate Along Kivumbini/Kalewa Road. NEMA. https://www.nema.go.ke/images/Docs/ EIA_1870-1879/ESIA_1871\%20Bondeni\%20 Housing\%20Appartments\%20SR\%202229min.pdf

Young-Corbett, D. (2012). Life Cycle Assessment (LCA) of Asbestos and Lead Building Materials in Schools: Goal and Scope Definition. In ICSDC 2011: Integrating Sustainability Practices in the Construction Industry (pp. 604610).

Zhang, Y. L., Kim, Y. C., \& Hong, W. H. (2016). Visualising distribution of naturally discharged asbestos fibers in Korea through analysis of thickness changes in asbestos cement slates. Journal of Cleaner Production, 112, 607619.

Zoraja, B., Živančev, M., Ubavin, D., \& NakomčićSmaragdakis, B. (2021, August). Circular economy as possible solution for asbestos burden. In IOP Conference Series: Materials Science and Engineering (Vol. 1163, No. 1, p. 012033). IOP Publishing.

47 | This work is licensed under a Creative Commons Attribution 4.0 International License. 